\title{
Characteristics of gravity waves observed with intensive radiosonde campaign during November-December 2005 over western Sumatera
}

\author{
M. Venkat Ratnam ${ }^{1,2}$, Simon P. Alexander ${ }^{3}$, T. Kozu ${ }^{4}$, and T. Tsuda ${ }^{1}$ \\ ${ }^{1}$ Research Institute for Sustainable Humanosphere (RISH), Kyoto University, Japan \\ ${ }^{2}$ National Atmospheric Research Laboratory (NARL), Gadanki, India \\ ${ }^{3}$ Australian Antarctic Division, Kingston, Tasmania, Australia \\ ${ }^{4}$ Faculty of Science and Engineering, Shimane University, Japan
}

(Received February 16, 2008; Revised April 22, 2009; Accepted May 13, 2009; Online published October 19, 2009)

\begin{abstract}
Characteristics of gravity waves are studied using radiosonde campaign conducted during NovemberDecember 2005 at Koto Tabang $\left(\mathrm{KT}, 0.2^{\circ} \mathrm{S}, 100.32^{\circ} \mathrm{E}\right)$. Intensive sounding with hourly launches was also conducted on seven days to study the characteristics of short period (2-6 hours) waves along with EAR data. Gravity waves with period $(\tau)$ of 3 hours and vertical wavelength $\left(\lambda_{z}\right)$ of $10 \mathrm{~km}$ seemed to be generated due to localized convection around KT, which is inferred from X-band Doppler radar. The energy of the gravity wave with period of 2-3 days and vertical wavelength of 3-5 km is largest between 15 and $20 \mathrm{~km}$ and 25 and $30 \mathrm{~km}$. We also report the comparison of the wave activity and its interaction with background wind between the three campaigns (CPEA-I, CPEA-II and Nov. 2002). Most of the time waves are propagating towards east and the source of gravity waves is strongly related to the slowly eastward-advecting tropospheric convection, implying that the wave activity was generated at far distant sources located west of KT. A key finding of this study is neither short period nor long-period gravity waves are generated during stationary type of convection. The change in the propagation direction of the short period waves within the event is observed which is not expected.
\end{abstract}

Key words: Gravity waves, convection, background wind, radiosonde campaign, EAR.

\section{Introduction}

The tropical atmosphere contains a number of spatial and temporal scales of motion. Modulation of these disturbances in the lower atmosphere will contribute significant variability in the upper atmospheric structure by transporting and depositing momentum and energy (Houghton, 1978; Lindzen, 1981; Holton, 1983; Warner and McIntyre, 1996; Fritts and Alexander, 2003 and references therein). This variability is poorly represented or absent in largescale models at present. Recent theoretical efforts have also addressed the penetration, behavior, and potential effects of these waves well into the thermosphere and suggest both neutral and plasma effects (Hines, 1960; Gurevich et al., 1997) that have yet to be confirmed by observations or detailed modeling studies. These many influences on momentum and energy transports, their forcing and imposed variability at higher altitudes, and the poor understanding and characterization of their many effects in GCMs and climate and forecast models provide the motivations for studying those using coordinated experiments. This would dramatically improve our knowledge of these dynamics on a global basis.

Among the various scales of waves, short period gravity waves (periods ranging from few minutes to few hours) are known to play important role in driving mean winds

Copyright (c) The Society of Geomagnetism and Earth, Planetary and Space Sciences (SGEPSS); The Seismological Society of Japan; The Volcanological Society of Japan; The Geodetic Society of Japan; The Japanese Society for Planetary Sciences; TERRAPUB. and thermal structures via transporting wave energy and momentum to middle and upper atmosphere (Garcia and Solomon, 1985; Hamilton, 1996; Alexander and Holton, 1997; Fritts and Alexander, 2003). Much progress has been made in delineating the characteristics of these waves with advent of highly sophisticated instruments in recent years. However, statistical properties of these waves are still uncertain due to various limitations in the current observational techniques.

Various sources are identified for the generation of these gravity waves and most of these sources are believed to be in tropospheric region (Fritts and Alexander, 2003 and references therein). Of considerable importance at tropical latitudes is the role of strong convection in forcing vertically propagating short-period gravity waves (known as convectively generated gravity waves). Various modeling and theoretical studies indicate that convectively generated gravity waves exhibiting relatively large vertical wavelengths $(>$ several $\mathrm{km}$ ) only play a major role in transporting the momentum into the higher altitudes (e.g., Horinouchi et al., 2002; Alexander et al., 2004; Beres et al., 2004). For studying the short period gravity waves and associated momentum fluxes one need high accuracy and high resolution measurements.

VHF Radar technique has proven as a powerful tool to study the characteristics of these short period gravity waves. It is a unique tool for continuous monitoring three dimensional wind components of atmosphere. However, it often suffers with low signal-to-noise ratio particularly in upper 


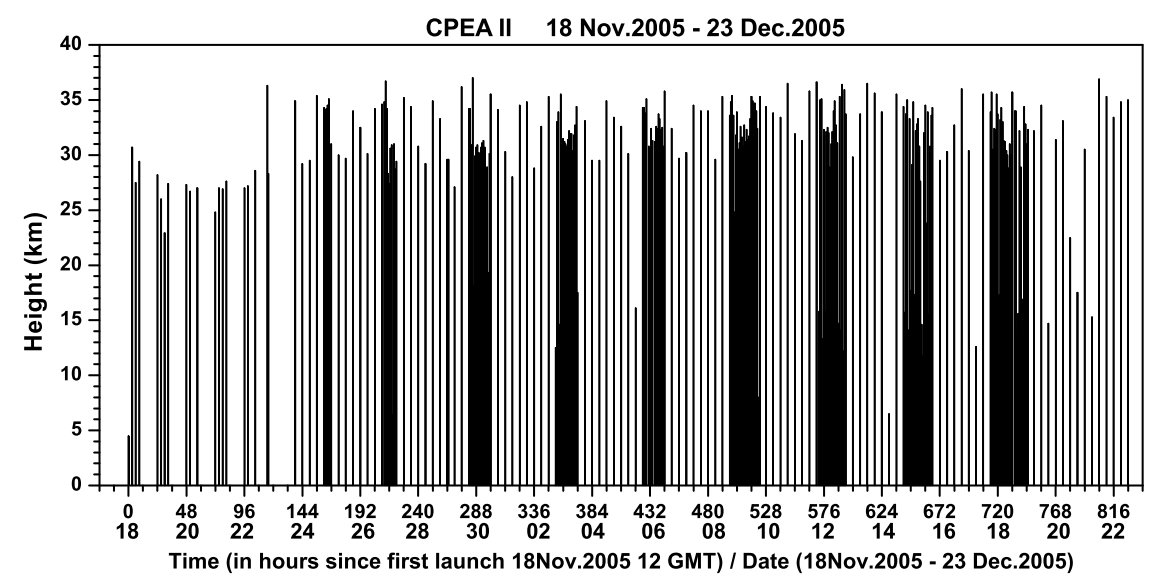

Fig. 1. Balloon burst height observed at Koto Tabang during CPEA-II campaign. Note that balloons were released four times a day. In addition, balloons were released every hour during 30-01 Dec., 3-4 Dec., 6-7 Dec., 9-10 Dec., 12-13 Dec., 15-16 Dec., 18-19 Dec. 2005.

troposphere and lower stratosphere, the region where these waves are generated, except near tropopause. Other ground based instruments have their own limitations for studying these short period gravity waves. For example, lidars could give the high resolution data but limited to night hours and clear sky conditions. Radiosondes are very much useful to probe upper troposphere and lower stratosphere but suffer with poor temporal resolution.

In order to overcome these limitations, a multiinstrumental program was conducted during the Coupling Process in Equatorial Atmosphere (CPEA) (Fukao, 2006) using a range of coordinated optical, radar, and in situ balloon measurements. As a part of this program, intensive radiosonde sounding were conducted for every 3 hours during CPEA-I campaign (Apr--May 2004). This data has been utilized to explore the characteristics of long-period gravity waves and associated source mechanisms (Ratnam et al., 2006a). However, it was noticed that this campaign is missing the important information on convectively generated short period gravity waves. In the second CPEA campaign conducted during Nov.-Dec. 2005, a much more intensive radiosonde campaign is conducted on seven days in which balloons were released for every hour by using three different receivers. In the present study we combine both very high temporal resolution EAR measurements and hourly radiosonde soundings to study the characteristics of short period gravity waves (2-6 hours).

\section{Experimental Set Up and Data Base \\ 2.1 Radiosonde launches}

An intensive radiosonde campaign was conducted over EAR site, Koto Tabang $\left(0.2^{\circ} \mathrm{S}, 100.32^{\circ} \mathrm{E}\right), \mathrm{KT}$, from 24 November-23 December, 2005 (hereinafter, referred to as the CPEA-II campaign). The balloons were released four times a day at KT, except on seven days (30-01 Dec., 3-4 Dec., 6-7 Dec., 9-10 Dec., 12-13 Dec., 15-16 Dec., 1819 Dec.'05) where balloons were released every hour for 19 times in first three IOPs, 25 times in next three IOPs and for 32 times in the last IOP. For launching every hour three receivers have been used. The consistency in the measurements obtained by different receivers has been checked and no discrepancy is observed in all the parameters. Total
279 balloons were released in a month time during CPEAII. Figure 1 shows maximum height (balloon burst height) reached by each balloon at KT during the CPEA-II campaign. On an average, 92\% (256) reached the tropical tropopause at about $17 \mathrm{~km}$, and 86\% (240) and 71\% (198) ascended higher than $25 \mathrm{~km}$ and $30 \mathrm{~km}$, respectively. Note that balloon burst generally occurs at lower altitudes during existence of deep convection which will be discussed in detail little bit later. All the atmospheric parameters were recorded every 2 seconds during the balloon ascent $(\sim 10 \mathrm{~m}$ height resolution), then the results were averaged for every $100 \mathrm{~m}$ height resolution. Later, quality checks were employed to remove outliers arising for various reasons (Tsuda et al., 2006), in order to ensure high quality in the data.

\subsection{Equatorial Atmosphere Radar (EAR) data}

We also collected EAR radar (Fukao et al., 2003) data located at $\mathrm{KT}\left(0.2^{\circ} \mathrm{S}, 100.32^{\circ} \mathrm{E}\right)$ which is available on continuous basis particularly during these IOPs in order to delineate the characteristics of short period gravity waves and compare with hourly radiosonde observations. The EAR provides information on 3-components of wind with a time resolution of three minutes. Wind data were measured between $2 \mathrm{~km}$ and $24 \mathrm{~km}$, however, above $20 \mathrm{~km}$ and between $14 \mathrm{~km}$ and $16 \mathrm{~km}$ the data were sparse, especially in the horizontal wind components. Height resolution of the EAR is $150 \mathrm{~m}$. The EAR data used for this analysis has temporal and height resolutions of 10 mints. and $150 \mathrm{~m}$, respectively.

\subsection{X-band Doppler Radar (XDR) observations}

We make use of XDR data which is at Sungai Puar $\left(0.36^{\circ} \mathrm{S}, 100.41^{\circ} \mathrm{E}, 1121 \mathrm{~m}\right.$ AMSL), located $20 \mathrm{~km}$ to the south-southeast of the EAR. It provides 3-dimentional reflectivity and velocity data for every 4 minutes with a spatial resolution of a few hundred meters. The reflectivity echoes were used as a proxy for the presence and strength of convection. Higher reflectivities indicate more active convection. The spatial and temporal evolution of the convection over an area of $120 \times 120 \mathrm{~km}$ could be studied with the XDR. For more details readers are referred to Kawashima et al. (2006). The cross-range resolution of the XDR at the EAR site was about $400 \mathrm{~m}$. The nine closest data points to the EAR site were averaged to produce a smoothed reflectivity value. 


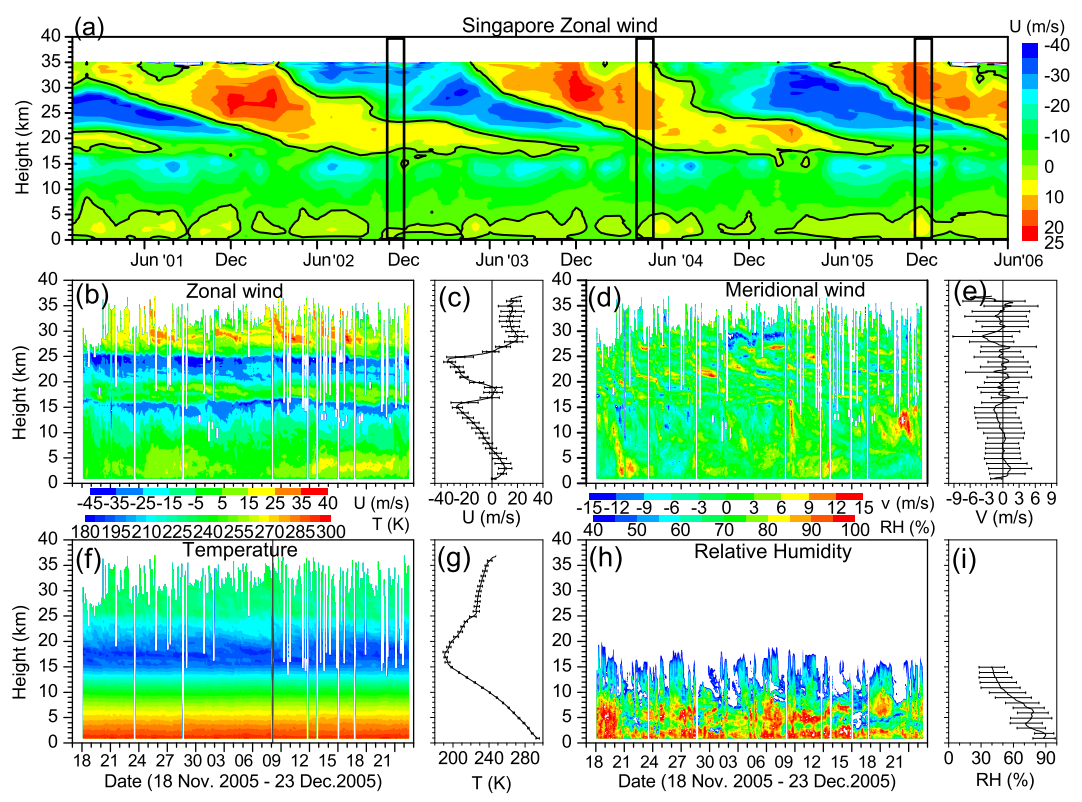

Fig. 2. Height-time cross section of (a) monthly mean zonal wind observed from January 2001 to June 2006 at Singapore. The vertical bars show the November 2002, CPEA-I (April-May 2004), and CPEA-II (November-December 2005) campaign periods conducted over Koto Tabang. Height-time sections of (b) zonal wind $(U)$, (d) meridional wind $(V)$, (f) temperature $(T)$, and (h) relative humidity $(R H)$ observed during CPEA-II campaign. Mean profiles of $T, U, V, R H$ averaged over the campaign period is plotted in (c), (e), (g), and (i), respectively.

\section{Background Conditions During CPEA-II Cam- paign}

\subsection{Background meteorological conditions}

Background conditions prevailing over the observation site are briefly mentioned in this section. Figure 2(a) shows the long-term monthly mean zonal wind between January 2001 and June 2006 observed at Singapore, indicating that the CPEA-II campaign period coincided with the change over from westward to eastward phase of QBO. Unlike CPEA-1 conducted during April-May 2004 (eastward phase of QBO), two strong shear zones were found: one around $15 \mathrm{~km}$ and other at $25 \mathrm{~km}$. The campaigns that were conducted during Nov. 2002, CPEA-I are also indicated in the figure.

Time height section of temperature, zonal and meridional wind, and relative humidity observed during the CPEA-II campaign are plotted in Figs. 2(b), 2(d), 2(f), and 2(h), respectively. Mean profiles of respective parameters along with standard deviation is plotted in Figs. 2(c), 2(e), 2(g), and 2(i), respectively. For this figure, all the available profiles including data from IOPs are used. During this entire campaign, not much variation in the background temperature can be noticed except near tropopause. The cold point tropopause was located at around $17.3 \mathrm{~km}$, and the corresponding temperature was $191.0 \mathrm{~K}$. The zonal winds were eastward below $7 \mathrm{~km}$ and above $27 \mathrm{~km}$ with peak amplitude of $20 \mathrm{~m} / \mathrm{s}$ (eastward phase of the QBO). They are westward in between 7 and $27 \mathrm{~km}$, except in-between 17 and $19 \mathrm{~km}$, with a peak amplitude reaching $40 \mathrm{~m} / \mathrm{s}$. Note that two strong shear zones existed one around tropical tropopause $(\sim 17 \mathrm{~km})$ and other around $25 \mathrm{~km}$ consistent with the westward phase of QBO shown in Fig. 2(a). Interesting thing to be noted in Fig. 2(c) is a small kink in the mean temperature profile around strong shear (at $\sim 25 \mathrm{~km}$ ) zone.

The mean meridional wind velocity was generally weak throughout the altitude region, even though some structures are recognized in the upper troposphere and lower stratosphere (UTLS) region. Large variability in the southward winds can be noticed at $27 \mathrm{~km}$. Significant variations in the humidity is observed during this campaign. There exists enhancement in the humidity around $5 \mathrm{~km}$ in addition to the enhanced humidity observed in the first few kilometers from surface. More than $50 \%$ of humidity can be noticed up to10 km during this campaign. The mean $N^{2}$ value (not shown here) was $\sim 0.5-2.0 \times 10^{-4}(\mathrm{rad} / \mathrm{s})^{2}$ below about $14 \mathrm{~km}$, which gradually increased through $15-18 \mathrm{~km}$, and became fairly constant at about $7.5 \times 10^{-4}(\mathrm{rad} / \mathrm{s})^{2}$ in the lower stratosphere $(<25 \mathrm{~km})$ and again decreased to $4.0 \times 10^{-4}(\mathrm{rad} / \mathrm{s})^{2}$ in the middle stratosphere.

\subsection{Background cloud conditions}

In addition to the XDR data mentioned in Section 2.3, we also make use of daily gridded outgoing long-wave radiation (OLR) provided by NOAA Climate Diagnostics Center website (http://www.cdc.noaa.gov). This data is used as proxy for tropical deep convection over large areas. Since convection was thought to be a main generation mechanism of various waves, a longitude-time section of OLR averaged between $2.5^{\circ} \mathrm{N}$ and $\mathrm{S}$ observed from 1 November-30 December, 2005 is shown in Fig. 3, including the CPEA-II campaign. Four super cloud clusters (SCCs), having horizontal scales greater than $2,000 \mathrm{~km}$, can be seen over the observational site during 21-22 Nov. 2005 (SCC1), 29-30 Nov. 2005 (SCC2), 11-14 Dec. 2005 (SCC3) and 21-22 Dec. 2005 (SCC4). Note that clear eastward motion from the Indian Ocean to the island of Sumatera can be seen, particularly during the SCC1 and SCC4 cases, whereas it is observed to be more or less stationary during SCC2 (quasi stationary) and SCC3. However, small patch of this cloud system seen around 10 December 2005 seem to propagate towards east from the observational site (not from Indian 


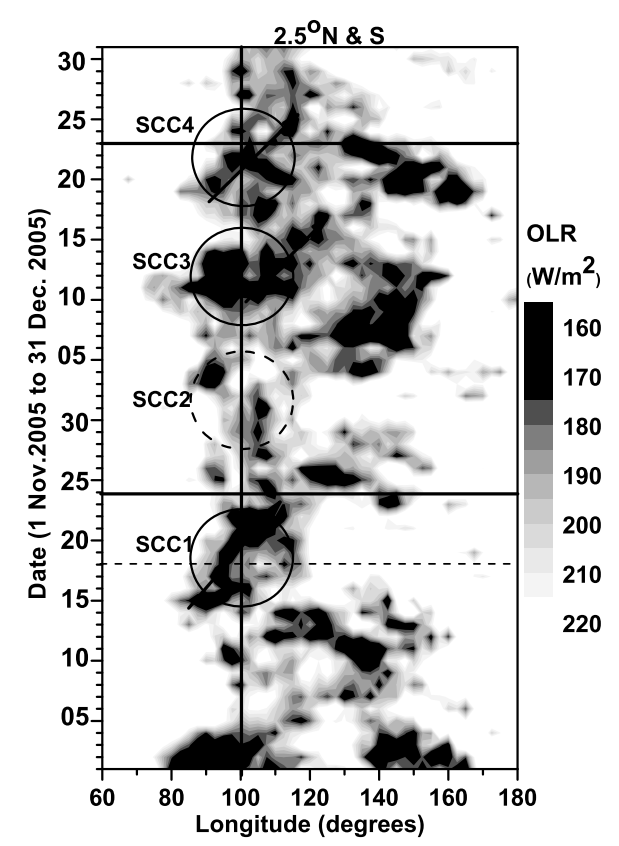

Fig. 3. Time-longitude section of outgoing long-wave radiation (OLR) over $2.5^{\circ} \mathrm{N}$ to $2.5^{\circ} \mathrm{S}$ during 1 November-31 December 2005 . Vertical line around $100^{\circ} \mathrm{E}$ shows the approximate location of Koto Tabang and horizontal lines indicate the CPEA-II campaign period. Note that although CPEA-II campaign started on 24 November 2005, observations are taken from 18 November 2005 (shown with dotted line).

Ocean). The average (from 24 Nov.-23 Dec. 2005) cloud top height (not shown here) estimated by converting OLR temperatures to the corresponding height from radiosonde measurements during the CPEA-II campaign was $8 \mathrm{~km}$, with maximum cloud top height of $16.5 \mathrm{~km}$. The cloud top height exceeded $13 \mathrm{~km}$ for about $6.1 \%$ unlike $15 \%$ observed during CPEA-I campaign. Complete details of cloud convection observed during Nov. 2002 and CPEA-I campaigns are provided in Ratnam et al. (2006b) and (2006a), respectively.

\section{Characteristics of Dominant Gravity Waves 4.1 High-pass filtered profiles}

Since one of the main focus of the present study is to characterize various waves during CPEA-II campaign, in the first we will deal with the long-period gravity waves (periods $<3$ days). Similar to the procedure followed by Ratnam et al. (2006a) for CPEA-I campaign for extracting these waves, we have subtracted the mean values at each altitude and then applied a high-pass filter with a cutoff at 3 days so that the effects of long-period waves (such as Kelvin waves) can be removed. Considering the dominant vertical wavelengths, further band-pass filtering was applied to the vertical profiles which passed vertical scales of 1$5 \mathrm{~km}$ in the troposphere and lower stratosphere, because the most dominant waves appear with vertical wavelengths of up to $3-4 \mathrm{~km}$. Note that still larger vertical wavelengths $(>6 \mathrm{~km})$ at these locations existed but mainly are associated with longer periods, typically for waves greater than several days. Since the time resolution of radiosonde launch is 6 hours (except during IOPs), the filtered fluctuations consist of the gravity waves with periods ranging from 12 hours to
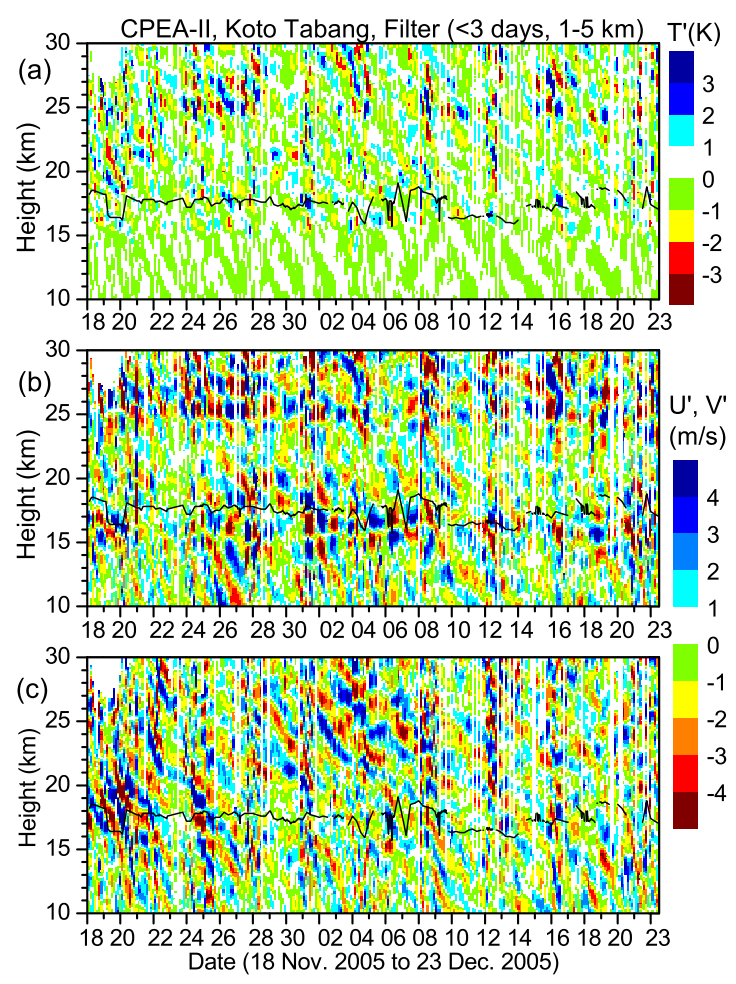

Fig. 4. Time height section of high-pass filtered profiles with cutoff at 3 days and band-pass filtered profiles with cutoff at 1 to $5 \mathrm{~km}$ in altitude of (a) temperature, (b) zonal, and (c) meridional wind observed at Koto Tabang during the CPEA-II campaign. Tropopause height observed during the campaign period is also superimposed (black line) in all the panels.

3 days with vertical wavelengths ranging from 1 to $5 \mathrm{~km}$ in the troposphere and lower stratosphere. Complete details of the analysis procedure implemented are discussed in Ratnam et al. (2006a).

Figure 4 shows the time-height section of high-pass filtered profiles of the temperature, zonal, and meridional winds observed at KT during the CPEA-II campaign. The variations are noticed to be significantly different between the troposphere and stratosphere. Clear downward phase propagation with a period of 2-3 days can be noticed in the lower stratosphere, whereas the troposphere shows a complex structure with mixed upward and downward phase propagation similar to that observed during CPEA-I campaign (Ratnam et al., 2006a). Unlike CPEA-I, the enhancement in the wave activity is observed at two different height regions. The amplitudes are particularly enhanced between 14-20 km altitude region and again between $25-30 \mathrm{~km}$ with largest amplitudes around $17 \mathrm{~km}$ and $26 \mathrm{~km}$, respectively, probably due to the interaction of background wind which will be discussed in detail in later sections. Another striking feature is that the enhancement of perturbations is not continuous but highly intermittent.

\subsection{Variation of gravity wave activity during CPEA-II campaign}

We have estimated the kinetic energy $\left(E_{\mathrm{k}}\right)$ per unit mass of the gravity waves by using the above obtained perturbations of wind velocity variance as follows:

$$
E_{\mathrm{k}}=\frac{1}{2}\left[\overline{u^{\prime 2}}+\overline{v^{\prime 2}}\right]
$$



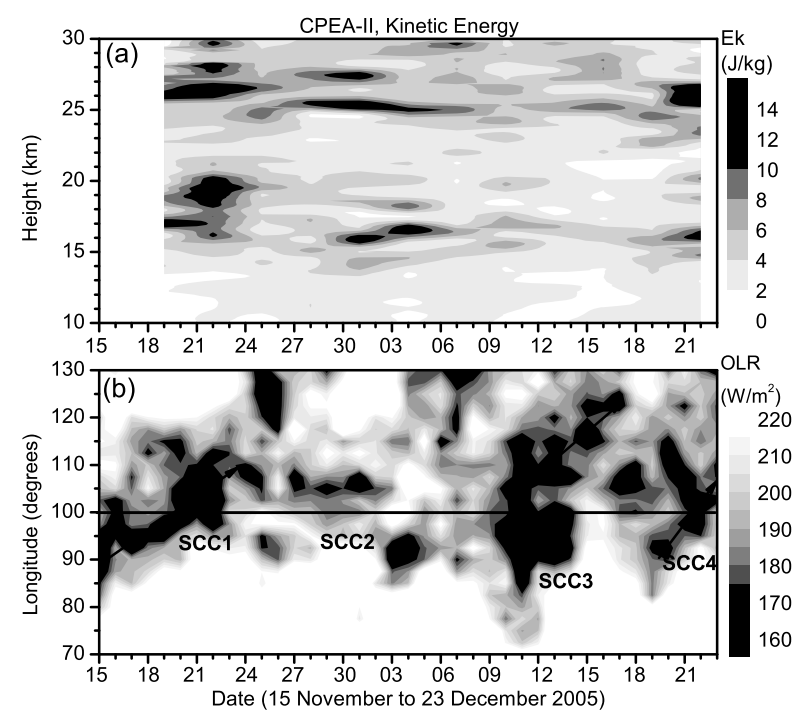

Fig. 5. (a) Height-time section of kinetic energy, $E_{\mathrm{k}}$, observed during CPEA-II campaign at Koto Tabang. (b) Longitude-time section of outgoing long-wave radiation (OLR) averaged in between $2.5^{\circ} \mathrm{N}$ and $2.5^{\circ} \mathrm{S}$ latitudes observed during same period.

where prime indicates the perturbation components, and the mean over $u^{\prime}$ and $v^{\prime}$ corresponds to the wind velocity perturbations for one-wave event, typically for a period of 2-3 days. Note that the effect of vertical wind velocity in Eq. (1) is neglected as its contribution is very small. Hereafter, $E_{\mathrm{k}}$ is treated as a measure of gravity wave activity.

Figure 5(a) shows the height-time section of $E_{\mathrm{k}}$ variations observed during the CPEA-II campaign at KT. As mentioned earlier, the gravity wave activity is significantly enhanced between 15 and $20 \mathrm{~km}$, and 25 and $30 \mathrm{~km}$ with the largest values at an altitude of around $19 \mathrm{~km}$ and $26 \mathrm{~km}$. They are particularly enhanced during the periods of 2024 Nov. 2005 (case 1), 30 Nov-4 Dec. 2005 (case 2), and at the end of the campaign (case 3). More or less similar behavior in the wave activity is also observed at Jambi and Padang (not shown here), where this campaign is extended by launching radiosondes for every 12 hours at these sites, and also at Singapore and Kuala Lumpur (routinely collected data but with $2 \mathrm{sec}$. and $4 \mathrm{sec}$. interval data set, respectively), with slight variation from station-to-station, giving evidence that the horizontal extent of the wave activity is more than the distance between the sites $(>430 \mathrm{~km})$. The eastward propagating cloud system shown in Fig. 5(b) is matching well the enhancement in the wave activity with a slight delay. However, during the stationary cloud systems, particularly during SCC3, no such enhancement in the wave activity is seen (this is also true for the first campaign). This indicates that there is some relation between the motion of source and wave activity in the UTLS region. Before investigating the location of the source region, we also estimated other characteristics (vertical and horizontal wavelengths, direction of propagation etc.) of these waves and are mentioned briefly below.

\subsection{Vertical wavelength and horizontal propagation} direction during CPEA-II campaign

The dominant vertical wavelengths $\left(\lambda_{z}\right)$ of the gravity waves can be directly inferred from the vertical profiles of temperature and wind velocity perturbations which is found (not shown here) to be about $4 \mathrm{~km}$ at all the sites during case 1 even though a broad band pass filter, which passes the waves with $1-5 \mathrm{~km}$, has been applied. The vertical wave number is estimated to be in between $1.7 \times 10^{-3}$ and $1.6 \times 10^{-3} / \mathrm{m}$ during case 2 and 3 events corresponding to $3.5 \mathrm{~km}$ and $4 \mathrm{~km}$, respectively.

During the CPEA-I campaign, the direction of propagation in horizontal and the dominant horizontal wavelengths $\left(\lambda_{h}\right)$ is obtained from cross correlative analysis (CCA) by using the simultaneous observations at other nearby sites which are located at about $\sim 75$ to $\sim 430 \mathrm{~km}$. Note that CCA analysis provides direction of propagation with respect to ground. On the other hand, hodograph analysis provides the wave propagation direction relative to the background winds. Because of weak mean winds during the CPEAI, the both estimates agreed relatively well (Ratnam et al., 2006a). For the CPEA-II campaign we have analyzed the direction of propagation using a hodograph. We tried to apply hodograph analysis to find the dominant direction of the propagation by using the perturbations obtained with cutoff at 3 days (time filter) and band pass filter profiles with cutoff at $1-5 \mathrm{~km}$. However, filtered profiles seem to be more wavy nature by this band pass filter and it was difficult to notice the orientation clearly from the hodograph analysis. Later, a narrow pass filter was applied by considering further dominant vertical wavelengths which passed waves with vertical wavelengths $3-4 \mathrm{~km}$ instead of $1-5 \mathrm{~km}$.

The hodograph obtained between zonal and meridional velocities is chosen as the propagation axis which is found to be north-east to south-west, north-west to south-east, and north-east to south-west directions during case 1, 2, and 3, respectively. Note that only profiles which show clear propagation axis are considered and the majority of the profiles thus selected from the total is only consider for this analysis similar to CPEA-I. The direction is further determined by investigating the relation between wind velocities and corresponding temperature gradient for individual profiles (Tsuda et al., 1994). For example, if the gradient in the temperature is positive near the positive/eastward perturbations in the zonal wind, then the direction is treated as eastward relative to the propagation axis. From this analysis the direction of propagation is found to be (not shown here) towards $45^{\circ}$ north from east during case $1,20^{\circ}$ south from east during case 2 , and $80^{\circ}$ north from east during case 3 .

Horizontal direction of propagation of the gravity waves (in percentage) sorted for every $30^{\circ}$ both in troposphere $(0$ $14 \mathrm{~km}$, left panel), lower stratosphere $(14-23 \mathrm{~km}$, middle panel), and in middle stratosphere (23-30 km, right panel) regions observed during entire CPEA-II campaign at Koto Tabang is shown in Fig. 6. Note that direction of propagation is westward most of the time during this campaign in the troposphere although eastward component is also noticed for $25 \%$ of cases. However, in the lower and middle stratosphere, the direction of propagation is seen always eastward most of the time. This suggests that most of the westward propagating waves are filtered near tropopause and only eastward propagating waves propagate to higher heights. This point will be discussed more in later sections. 


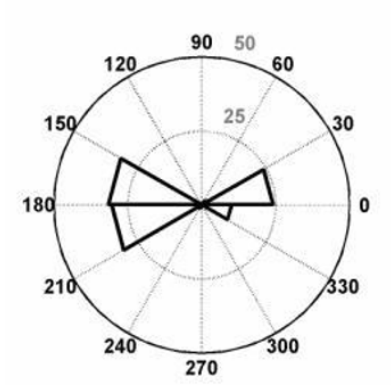

$(0-14 \mathrm{Km})$

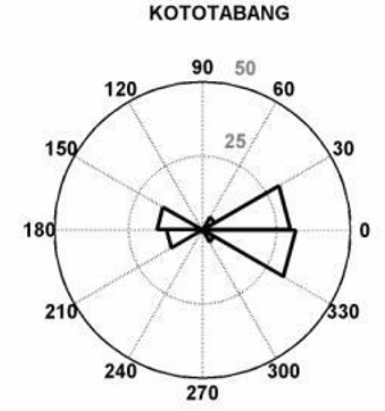

$(14-23 \mathrm{Km})$

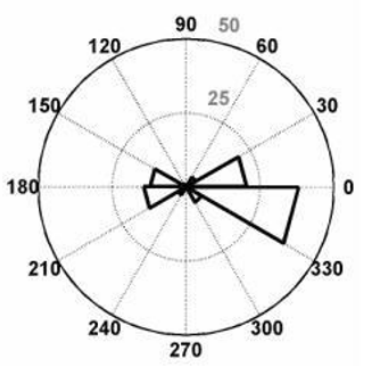

$(23-30 \mathrm{Km})$

Horizontal Phase Propagation Direction

Fig. 6. Horizontal direction of propagation of the gravity waves (in percentage) sorted for every $30^{\circ}$ both in troposphere (0-14 km, left panel), lower stratosphere (14-23 km, middle panel), and in middle stratosphere (23-30 km, right panel) regions observed during CPEA-II campaign at Kototabang. Number of samples considered is 76,82 and 65 for $0-14 \mathrm{~km}, 14-23 \mathrm{~km}$, and $23-30 \mathrm{~km}$, respectively. $0^{\circ}, 90^{\circ}, 180^{\circ}$, and $270^{\circ}$ are assigned as eastward, northward, westward, and southward directions, respectively. Inner and outer circles are drawn at $25 \%$ and $50 \%$ occurrences, respectively.

\subsection{Vertical and horizontal group velocities}

The horizontal and vertical phase velocities $\left(C_{\mathrm{p} H}\right.$ and $C_{\mathrm{pZ}}$ ) relative to the mean flow are determined and the vertical and horizontal group velocities are further estimated depending upon the propagation direction by incorporating the observed vertical and horizontal wave numbers (Tsuda et al., 1994). The horizontal wave number $(k)$ is determined using the dispersion relation between vertical wave number $(m)$, intrinsic frequency $(\omega)$ and Brunt Väisälä frequency $(N)$ i.e., $k=m \omega / N$. Since Koto Tabang is close to equator, we cannot estimate $\omega$ through dispersion relation alone. To solve this problem we have used cross correlation analysis (CCF) (Ratnam et al., 2006a) by considering nearby stations (Jambi, Padang, Singapore, Kula Lumpur) to estimate the $k$. This information is used to estimate the $\omega$ from known $m$ and $N$ in the above equation. We further estimated phase velocity relative to the background mean wind using the relation $C=U+\frac{\omega}{k}$, where $C$ is the phase velocity; $U$ is background mean winds in the direction of wave propagation which is found from hodograph analysis. The vertical group velocity $\left(C_{\mathrm{g} Z}\right)$ is estimated to be in the range of $0.5-2 \mathrm{~km} /$ day, with peak values occurring between 1 and $1.5 \mathrm{~km} /$ day. In particular, the vertical group velocity estimated during case 1 , case 2 , and case 3 is about $1.5 \mathrm{~km} /$ day, $1.2 \mathrm{~km} /$ day, and $1.6 \mathrm{~km} /$ day, respectively. Note that the value of $N$ is taken as constant from radiosonde observations at $\sim 20 \mathrm{~km}$ altitude since this value is not varying much at these heights. Similarly, the horizontal group velocity $\left(C_{\mathrm{g} H}\right)$ is estimated to be in the range of $700-1800 \mathrm{~km} /$ day with peak values occurring around $1300 \mathrm{~km} / \mathrm{day}$. It is observed to be $1500 \mathrm{~km} / \mathrm{day}, 1000 \mathrm{~km} / \mathrm{day}$, and $1100 \mathrm{~km} / \mathrm{day}$ during case 1 , case 2 , and case 3 , respectively. It is to be noted that these group velocities are those relative to the mean wind.

\section{Gravity Wave Interaction with Background Wind}

We also made comparison in the wave activity between the three campaigns (Nov. 2002, CPEA-I and CPEA-II) and is presented in Fig. 7 along with background conditions.
Same analysis is utilized to study the gravity wave interaction with the background wind by using three campaigns data conducted during different phases of QBO (shown in Fig. 2(a)). Note that mean zonal wind (shown in left panels) during the Nov. 2002 and CPEA-II is in westward direction throughout the height region, except between 17 and $23 \mathrm{~km}$ during Nov. 2002 campaign, and below $7 \mathrm{~km}$ and $17-19 \mathrm{~km}$, and above $27 \mathrm{~km}$ during CPEA-II campaign. However, during CPEA-I campaign, it is westward below $17 \mathrm{~km}$ and changes to eastward above it. As a result, two strong shear zones can be noticed from the middle right panel. Only difference between Nov. 2002 and CPEA-II campaigns is that existence of eastward shears at both heights during CPEA-II but one eastward shear near $17 \mathrm{~km}$ and other showing westward shear around $23 \mathrm{~km}$ during Nov. 2002. Mean meridional winds superimposed in left panels are very weak in all the three campaigns. Mean $N^{2}$ profiles shown in middle left panels show similar structures, although they differ in amplitude, except in the lower stratosphere where pronounced peak is noticed during CPEA-II campaign. Note that $N^{2}$ structure does not explain height variations of $E_{\mathrm{k}}$.

Notable features to be observed are the enhancements in the wave activity near the zones of strong zonal wind shears and overall wave activity is higher in CPEA-I campaign followed by Nov. 2002 and CPEA-II campaigns. The averaged cloud convection over a month period shows (not shown here) enhanced deep convection during Nov. 2002 and CPEA-II (being conducted in same month although years are different) and less during CPEA-I. Nevertheless, deep convective events are more during CPEA-I (also inferred from cloud top height) than other two campaigns hence more wave activity during CPEA-I than CPEA-II. Height distribution of the wave energy seems to correlate with the structure of the mean zonal wind shear. This shows there exists strong interaction of these waves with the background wind. However, the amplitudes of $E_{\mathrm{k}}$ did not correlate with the shear intensity. Note that enhanced wave activity is clearly observed during the eastward wind and not seen during westward wind. 


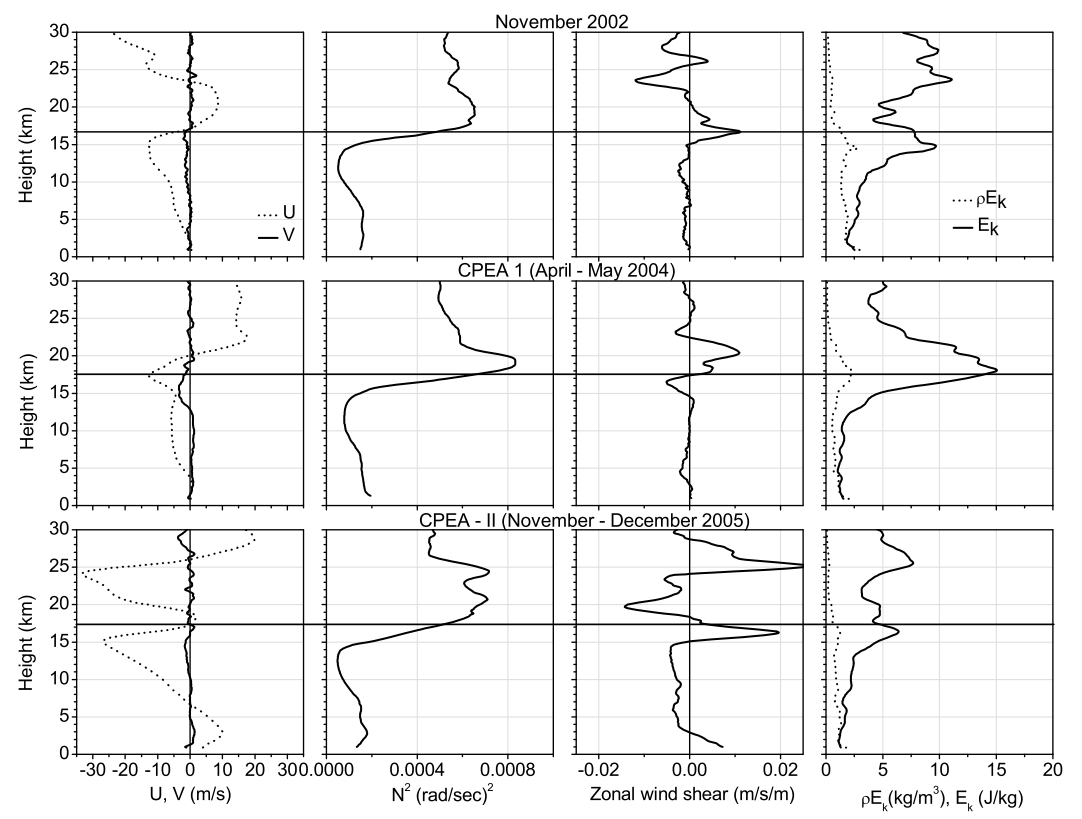

Fig. 7. Profiles of the mean zonal and meridional wind (left), Brunt Väisälä frequency square, and the zonal wind shear (center two panels), and the mean $E_{\mathrm{k}}$ (solid line) and density multiplied $E_{\mathrm{k}}$ (dotted line) profiles (right) averaged for the three campaign periods conducted during November 2002 (top), CPEA-I (middle), CPEA-II (bottom).
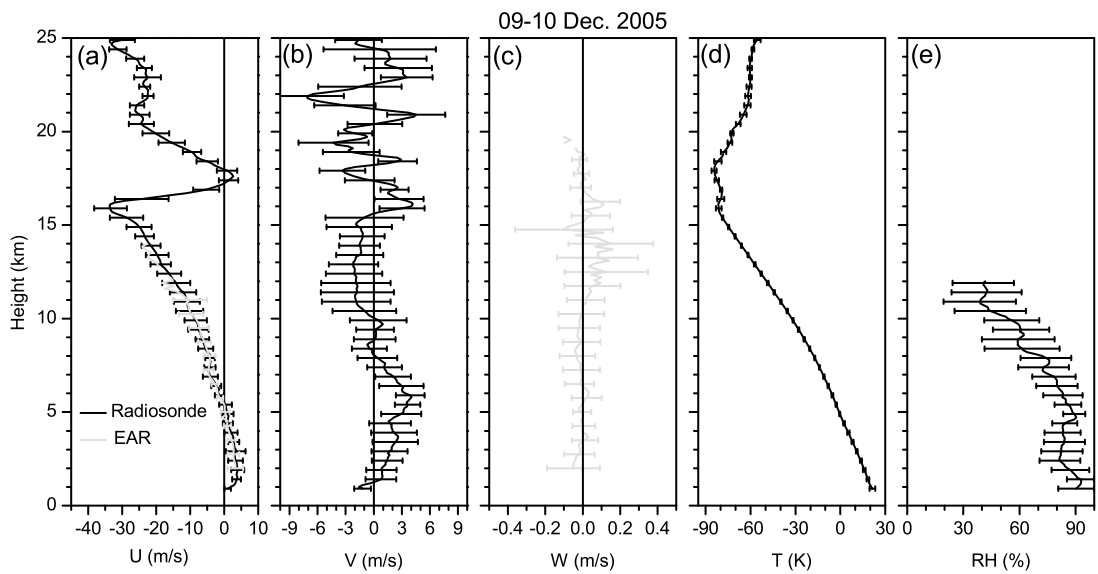

Fig. 8. Profiles of diurnal mean (a) zonal, (b) meridional, and (c) vertical velocities observed on 9-10 Dec. 2005 by EAR. Radiosonde profiles averaged during the same period launched at every hour is also superimposed in the same panels. Profiles of temperature and relative humidity observed by radiosonde are shown in (d) and (e), respectively. Horizontal bars denote the standard deviation obtained while averaging over a day.

\section{Short Period ( $<6$ Hours) Gravity Wave Charac- teristics Observed Using Combined Measure- ments of EAR and Hourly Radiosonde Sound- ings}

Balloons released for every 6 hours has been utilized effectively to study the characteristics of dominant period gravity waves and associated source mechanisms. However, it was noticed that this campaign is missing the important information on convectively generated short period gravity waves. As mentioned earlier, in CPEA-II campaign, a much more intensive radiosonde campaign is conducted on seven days in which balloons were released for every hour by using three different receivers. In the present study we combine both very high temporal resolution EAR measurements and hourly radiosonde soundings to study the characteristics of short period gravity waves ( $<6$ hours). In total 159 profiles which has reached grater than tropical tropopause height (about $17 \mathrm{~km}$ ) were successfully collected.

\subsection{Comparison between EAR and radiosonde wind fields}

Since we are combing both EAR $(<12 \mathrm{~km})$ and radiosonde (up to $30 \mathrm{~km}$ ) measurements to study the characteristics of shorts period gravity waves, it is essential to compare their parameters in the overlapping regions. For comparing EAR derived winds with that estimated with radiosonde, half an hour before and after the launch of balloon has been averaged for EAR. Figure 8(a)-(c) shows the profiles of diurnal mean zonal, meridional, and vertical winds observed by EAR on 09-10 Dec. 2005. Profiles of radiosonde are also superimposed in the zonal and meridional components. A very good consistency between these two different techniques can be noticed in the overlapping regions. As expected radiosonde profiles are within the standard deviation of EAR winds averaged over that particular 


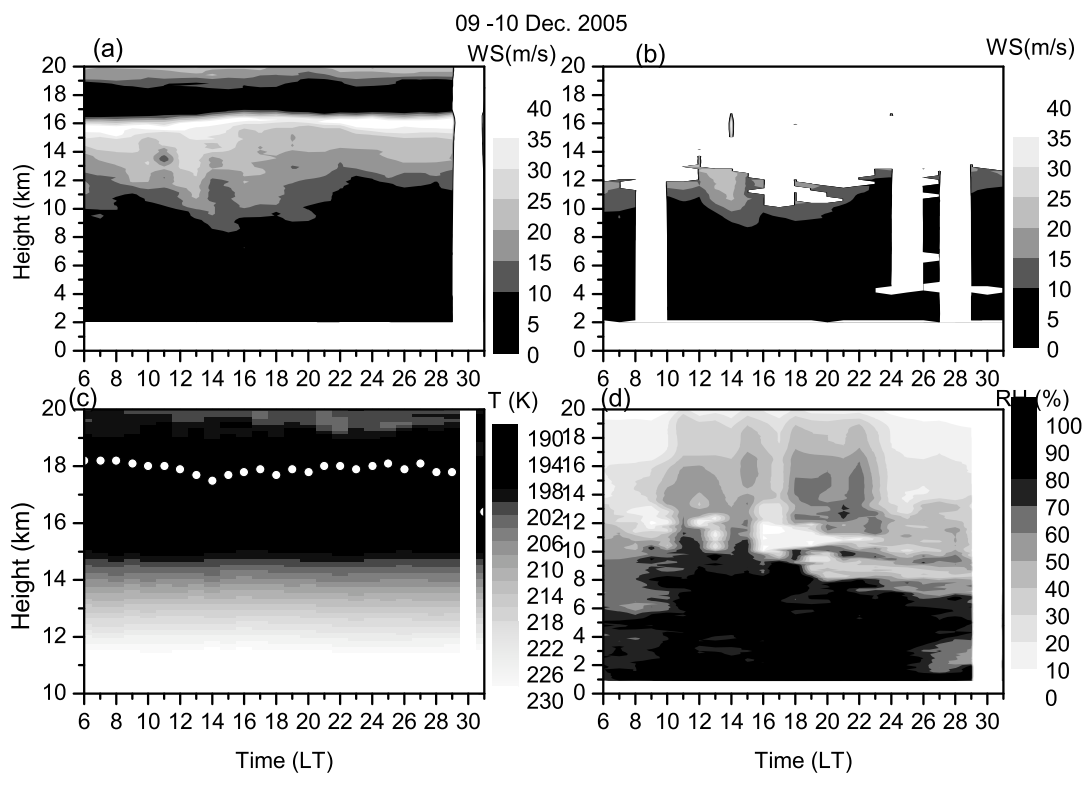

Fig. 9. Time-height section of (a) wind speed, (c) temperature, and (d) relative humidity observed by radiosonde on 09-10 Dec. 2005. Filled circles in (c) denote the tropopause height. Wind speed observed by EAR on the same day is plotted in (b).

hour and in a day. Although not clear from this figure, good comparison is also seen near the tropopause height, however, there is a gap between 14 and $16 \mathrm{~km}$. In general, more often this gap is seen in EAR data which is due to low signal-to-noise ratio (SNR). Nevertheless, there exists slight shift above $11 \mathrm{~km}$ which is expected due to problems in resolving the wind components in low SNR conditions in case of EAR. More often large bias between these two different techniques is observed in between 12 and $15 \mathrm{~km}$ and the details are out of scope of present study. Eastward winds up to $5 \mathrm{~km}$ and westward $(-40 \mathrm{~m} / \mathrm{s})$ above, except around $17 \mathrm{~km}$, can be noticed with strong shears between 16 and $17 \mathrm{~km}$. Meridional and vertical winds are showing wavy nature sometimes showing northward and southward, downward and upward, respectively. The diurnal mean profiles of temperature and relative humidity along with standard deviation observed by radiosonde are shown in Figs. 8(d) and 8(e), respectively. Temperature profile reveals the existence of double tropopause (or modulation of the tropopause by wave effects) on this day. Humidity profile plotted in Fig. 8(e) show more humid even up to $12 \mathrm{~km}$.

Diurnal variation of wind speed, temperature, and relative humidity observed on 09-10 Dec. 2005 by radiosonde is shown in Fig. 9. Wind speed observed by EAR on the same day in Fig. 9(b) also show good consistency with that observed by radiosonde even on hour-to-hour basis. EAR observations were not available above $12-13 \mathrm{~km}$ on this day but the good consistency in the observed structures between EAR and radiosonde provides an opportunity to study the gravity wave activity up to $30 \mathrm{~km}$. High time resolution observations available from EAR also helps in looking the detailed characteristics of gravity waves.

Except small decrease in the temperatures during night time near surface, no strong diurnal variation in temperature obtained from radiosonde is noticed up to the tropopause on this day which is shown in Fig. 9(c). However, tropopause height plotted in the same panel show some diurnal vari- ation (about $700 \mathrm{~m}$ ) with higher $(18.2 \mathrm{~km})$ and lower $(17.5 \mathrm{~km})$ heights during afternoon to evening and night times, respectively. Variations in relative humidity plotted in Fig. 9(d) show large diurnal variation with maximum humidity up to $8 \mathrm{~km}$ during evening to next day morning. More or less similar kind of variations is noticed even in other IOPs.

\subsection{Gravity wave activity observed with EAR}

Gravity wave events were seen on many days, but, intensive radiosonde sounding coincided well in one case i.e., on 09-10 Dec. 2005. Here we briefly mention about the analysis procedure which was adopted to extract gravity waves parameters. Data with one day before and after the intensive sounding day has been averaged and is defined as background mean profile. This mean profile is removed from each instantaneous profile to get fluctuation component. Spectral plot show (not shown here) the dominant oscillation around 3 hours with vertical wavelengths greater than $5 \mathrm{~km}$. Later high-pass filter with cutoff at 6 hours and low-pass filter with cutoff at $5 \mathrm{~km}$ was applied to the fluctuation component.

Time height section of fluctuations in zonal, meridional, and vertical components obtained from EAR observations with high-pass filter in time and low-pass filter in vertical is shown in Fig. 10. Note that the fluctuations are shown during 8-11 Dec. 2005 i.e., including one day before and after the IOP of 9-10 Dec. 2005. The reflectivity obtained during 8-11 Dec. 2005 from X-band Doppler radar is also plotted in the bottom panel of Fig. 10. In relation to large reflectivity reaching as high as $12-13 \mathrm{~km}$, enhanced wave activity can be noticed in all the components of wind field. Large perturbations during noon of 8 Dec. 2005 lasting for several hours are clearly observed. Similar features are also noticed on 9-10 Dec. 2005 but unfortunately there was data gap in X-band Doppler radar. However, increase in the reflectivity is also observed during this day. The amplitudes are of $2 \mathrm{~m} / \mathrm{s}$ in zonal and meridional component 


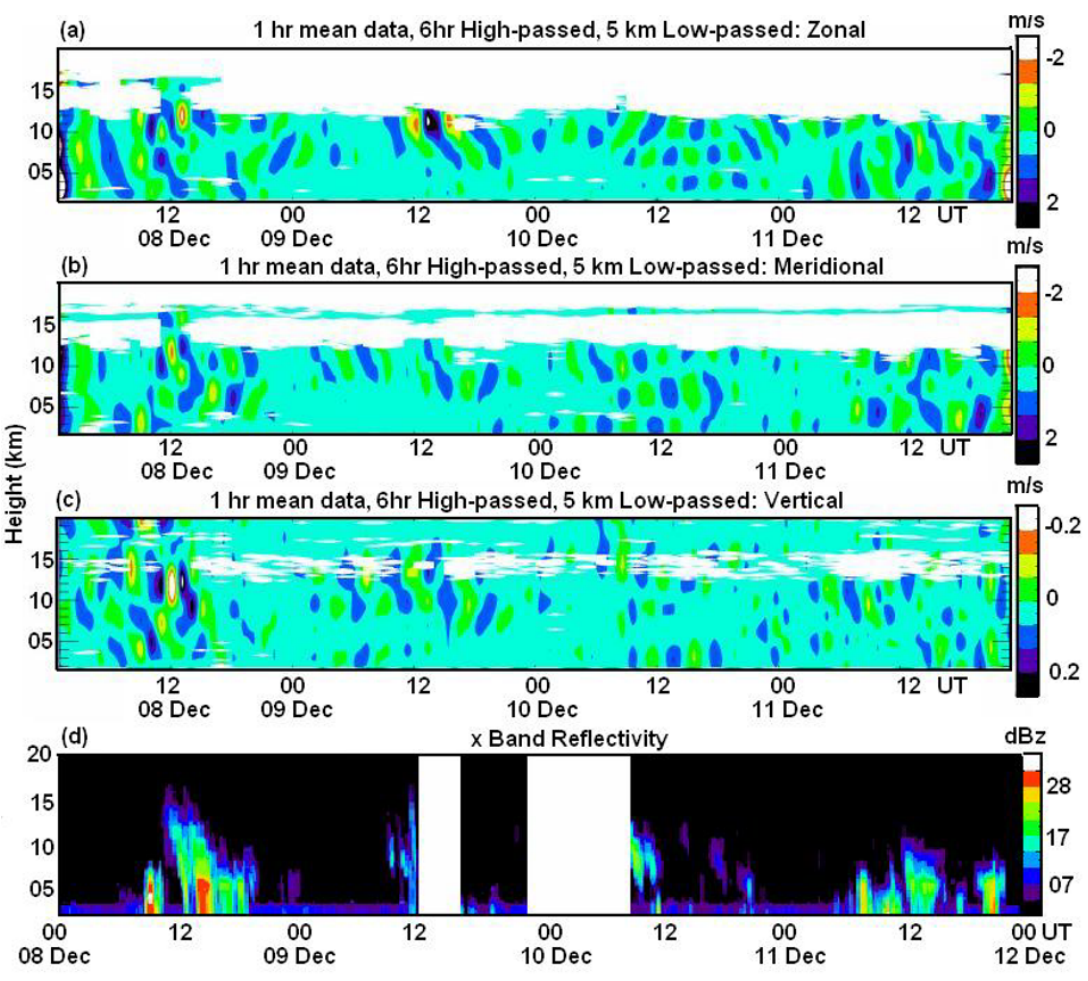

Fig. 10. Time-height sections of high-pass filtered profiles with cut off at 6 hours and low-pass filter with cut off at $5 \mathrm{~km}$ in (a) zonal, (b) meridional, and (c) vertical components of EAR during 8-11 Dec. 2005. Note that during 9-10 Dec. 2005 intensive radiosonde balloon at every one hour is launched. (d) Time-height section of $\mathrm{X}$ band Doppler radar observed reflectively during the same period.

and $0.2 \mathrm{~m} / \mathrm{s}$ in vertical component. Although it is better in vertical component, note that the wave activity is seen up to $12-13 \mathrm{~km}$ only from EAR. It is not known how the structures behave above this altitude from EAR alone. In this situation, intensive soundings conducted for every hour are very useful to get detailed information up to $25-30 \mathrm{~km}$. 6.3 Gravity wave activity observed with hourly radiosonde

Similar analysis that was carried out by EAR is followed to extract the gravity wave parameters with hourly radiosonde launches. Time-height section of high-pass filter with cutoff at 6 hours and low-pass filter with cut of at $5 \mathrm{~km}$ in zonal component of radiosonde data observed during 910 Dec. 2005 is shown in Fig. 11. Note that enhanced wave amplitudes showing downward propagation (upward propagation of energy) is clearly noticed up to $20 \mathrm{~km}$ (which was not possible to see with EAR observations) with peak value located at $12 \mathrm{~km}$. Note that no significant amplitudes are noticed above $16 \mathrm{~km}$, the region of strong shear, although it seems to be connected up to $20 \mathrm{~km}$. The dominant period is observed to be 3 hours with vertical wavelength of about $10 \mathrm{~km}$ from the top and right panels of Fig. 11. These periods and vertical wavelengths are plotted at $12 \mathrm{~km}$ and 13 UT, respectively.

The relation between temperature and horizontal wind perturbations (hodograph) can be used to get the information on direction of propagation (Ratnam et al., 2006a). The perturbation components of temperature, zonal and meridional velocities observed on 9 Dec. 2005 during the enhanced wave amplitudes is shown in Fig. 12. The hodograph plotted between zonal and meridional components show that the propagation axis is towards north-west to south-east in first two hours but changes to north-east to south-west and again back to north-west to south-east. The information in the gradient in temperature is used to locate exact direction of propagation (Tsuda et al., 1994; Ratnam et al., 2006a) in which it shows north-west in first two hours changing to north-east and later to south-east direction. Similar features are also noticed from EAR zonal and meridional wind perturbations (not shown here). This kind of rotation in the direction within the event is not expected which is to be investigated further, however other wave generated due to other convective source in and around but propagated towards observational site could be one of the reasons for the observed sudden change in the direction.

\section{Summary and Conclusion}

As in CPEA-I campaign, intensive balloon soundings conducted over Koto Tabang during the CPEA-II campaign has been used to delineate the characteristics of various gravity waves. During this campaign, four super cloud clusters (SCCs) developed in the Indian Ocean and two of them passed through the observational sites on November 21-22 and December 21-22, 2005 (Fig. 3).

The gravity wave activity with periods 2-3 days and vertical wavelength of $3-5 \mathrm{~km}$ is found to be significantly enhanced during 21-23 November 2005 (case 1), 30 November-2 December 2005 (case 2), and 21-22 December 2005 (case 3), with peak activity around 22 November 2005, 1 December 2005, and 22 December 2005, respectively (Fig. 5). This enhancement is not continuous but is highly intermittent. These waves seem to start enhancing 


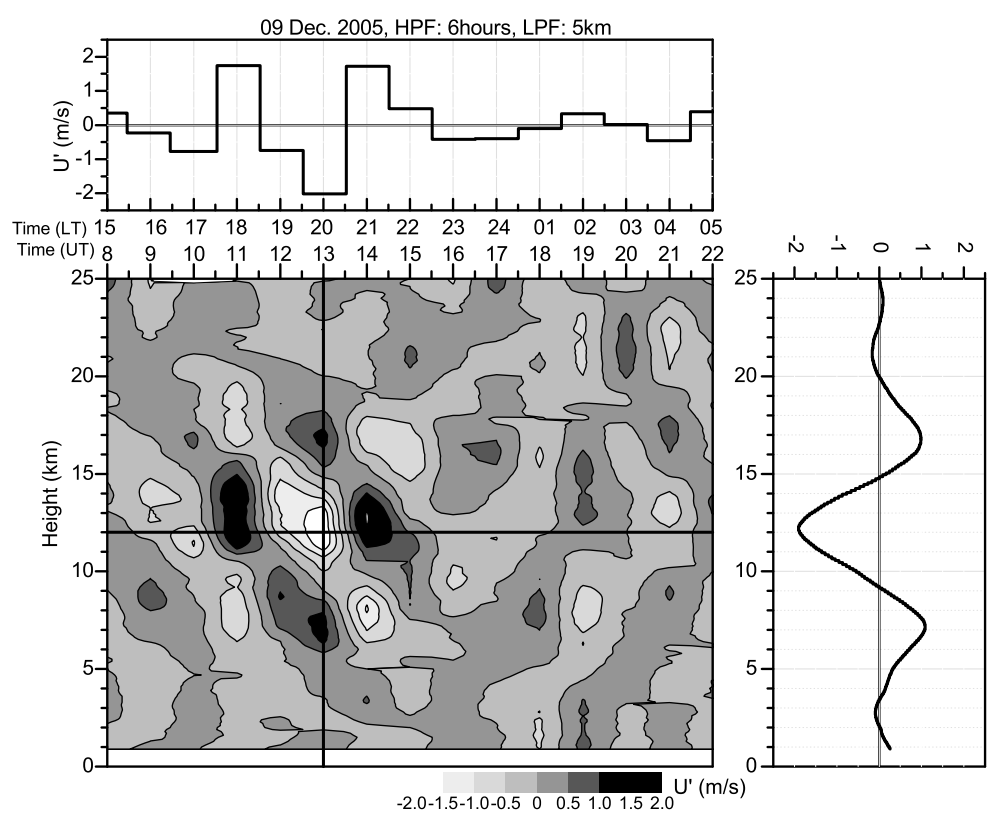

Fig. 11. Time-height variations of high-pass filtered profiles with cut off ant 6 hours and low-pass filter with cut off at $5 \mathrm{~km}$ in zonal component of radiosonde data observed during 9-10 Dec. 2005. Top and right panels show the time series and profile of filtered zonal wind at $12 \mathrm{~km}$ and 13 UT, respectively.

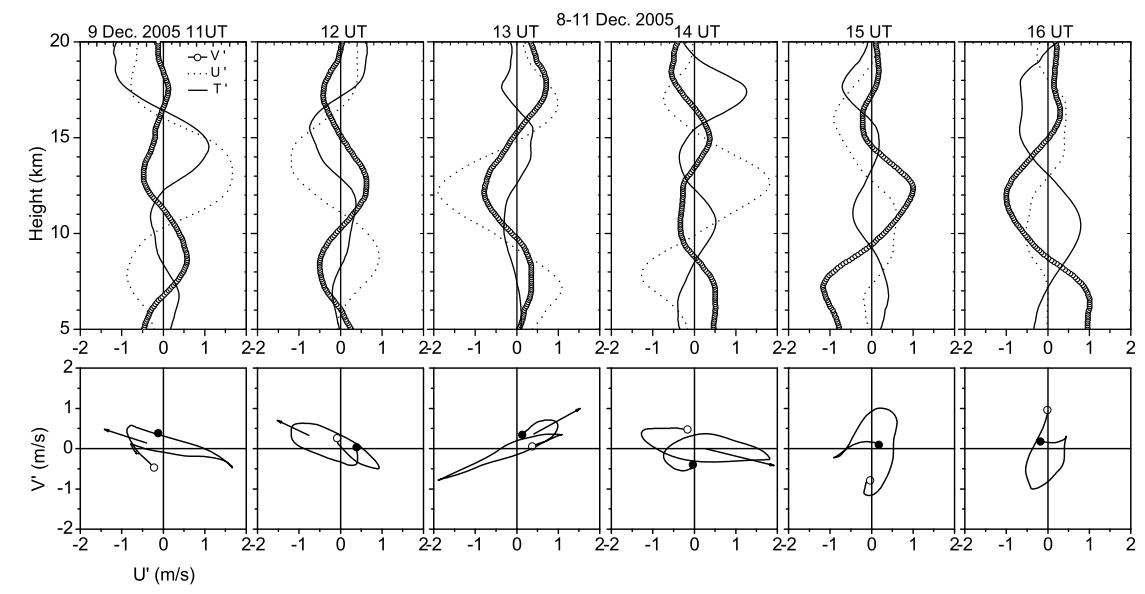

Fig. 12. Perturbation components in temperature, zonal and meridional velocities observed by radiosonde at Koto Tabang on 9 Dec. 2005 from 11 UT to 16 UT. Bottom panels show the hodograph obtained between 5 and $20 \mathrm{~km}$, which is the region in which enhanced perturbations are noticed from the top panel. Filled and open circles denote the starting and ending point in the hodographs. The arrows represent exact direction of propagation. Note that length of the arrow does not have any meaning.

from $14 \mathrm{~km}$ upwards, most likely due to consistent increase in the background $N^{2}$, and start dissipating above $20 \mathrm{~km}$ altitude region, with peak wave energy occurring around $20 \mathrm{~km}$, the region of maximum zonal wind shear. There is another enhancement around $25 \mathrm{~km}$ which is arising mainly due to background wind conditions.

The dominant direction of propagation of these waves in the troposphere was westward although sometimes it seems to be propagating towards east. However, only eastward (either north-east or south-east) in the lower stratosphere in all the cases was noticed. This suggests that the westward propagating waves are filtered by the background westward winds near the tropopause.

Since the ratio of vertical to horizontal group velocity is small for these waves compared to higher frequency waves, the source can be found at larger horizontal distances (e.g.,
Vincent and Alexander, 2000). In order to find the source for these waves, satellite OLR data is used as a proxy for tropical deep convection. As observed during CPEA-I campaign, the horizontal distribution scale of cloud amount is found (not shown here) to be comparable to the horizontal wavelength of the dominant gravity waves located to the west of Sumatra Island. It is quite interesting to notice clear eastward advection from the Indian Ocean to Sumatra Island occurred during SCC1 and SCC4 but not clearly in SCC2 and motion is absent in SCC3. Similar to the CPEAI, the enhancement of $E_{\mathrm{k}}$ coincides with the motion of the convective centers, particularly in the case 1 (SCC1) and 3 (SCC4). Small enhancement in the wave activity is observed during quasi stationary cloud convection (SCC2).

Enhancements in the wave activity is observed near the zones of strong zonal wind shears and overall wave activ- 
ity is higher in CPEA-I campaign followed by Nov. 2002 and CPEA-II campaigns. Height distribution of the wave energy seems to correlate with the structure of the mean zonal wind shear. This shows there exists strong interaction of these waves with the background wind. Another interesting feature noticed is that existence of westward wind though the year around $15 \mathrm{~km}$ altitude from Fig. 2(a). It is not so surprising to notice the eastward propagation most of the time in UTLS region since westward wind is persisted around $15 \mathrm{~km}$ altitude, only the eastward component of the wave is expected to propagate upward, hence most of the time only eastward propagation is observed. Then question arises how these gravity waves can influence the westward phase of QBO which needs to be further investigated by considering the longitudinal variation or other period gravity waves.

The behavior of short period ( $<12$ hours) gravity waves is also analyzed by means of a very intensive radiosonde campaign, EAR, and XDR observations during Nov.-Dec. 2005 at Equatorial Atmosphere Radar $(0,100.3 \mathrm{E})$ in Indonesia. Although seven IOPs were conducted during Nov.-Dec. 2005 and the gravity wave events were seen on many days, intensive radiosonde sounding coincided well in two cases i.e., on 09-10 Dec. 2005 and with smaller amplitudes on 30 Nov.-1 Dec. 2005. Dominant gravity waves with 3 hours period, and $10 \mathrm{~km}$ vertical wavelengths with downward phase propagation is clearly detected in the upper troposphere using EAR measured wind components with significant amplitudes in relation to cloud convection observed by X-band Doppler radar. However, same event extending to lower stratosphere (UTLS) region (up to $20 \mathrm{~km}$ ) is clearly noticed from hourly radiosonde soundings although maximum amplitudes are noticed below $16 \mathrm{~km}$ just near strong shear zone. The direction of propagation is found to be changing within the event, which is not expected, from north-west to south-east. Since amplitudes of the observed gravity waves are very small, it is difficult to analyze gravity wave characteristics and related parameters in detail. Some modeling studies have to be carried out to investigate why there will be change in the direction of propagation within the event.

Interesting thing noticed is that neither long-period (23 days) nor short period ( $<6$ hours) gravity wave has been observed over Koto Tabang during stationary type of convection (SCC3). There is a possibility that the waves might have propagated to the directions other than Koto Tabang. Perhaps very short period (30 mints-1 hour) gravity waves might have been generated during this period. Observations from EAR radar can be used to study these waves, but, data is not available many times above $12 \mathrm{~km}$, expect near tropopause and is impossible to notice from this hourly data set from radiosonde.

Acknowledgments. The authors would like to thank all of the people who helped to make the CPEA campaign a success. We thank S. Mori for providing Nov. 2002 campaign data and Debasish Nath for helping in data analysis. Discussion with Dr. Horinouchi is highly appreciated. One of the authors (MVR) wishes to thank the Japan Society for Promotion of Science (JSPS) for providing a fellowship to carry out this work. The CPEA campaign is supported by the Japanese Ministry of Education, Culture,
Sports, Science and Technology (MEXT) through a Grant-in-Aid for Scientific Research in Priority Areas (Grant number: (A03) 13136206; (A04) 13136203). We thank two anonymous reviewers for their suggestions/comments which made us to improve the manuscript.

\section{References}

Alexander, M. J. and J. R. Holton, A model study of zonal forcing in the equatorial stratosphere by convectively induced gravity waves, J. Atmos. Sci., 54, 408-419, 1997.

Alexander, M. J., P. T. May, and J. H. Beres, Gravity waves generated by convection in the Darwin area during the Darwin Area Wave Experiment, J. Geophys. Res., 109, D20S04, doi:10.1029/2004JD004729, 2004.

Beres, J. H., M. J. Alexander, and J. R. Holton, A method of specifying the gravity wave spectrum above convection based on latent heating properties and background wind, J. Atmos. Sci., 61, 324-337, 2004.

Fritts, D. C. and M. J. Alexander, Gravity wave dynamics and effects in the middle atmosphere, Rev. Geophys., 41(1), 1003, doi:10.1029/ 2001RG000106, 2003.

Fukao, S., Coupling Processes in the Equatorial Atmosphere (CPEA): A project overview, J. Meteor. Soc. Jpn., 84A, 1-18, 2006.

Fukao, S., H. Hashiguchi, M. Yamamoto, T. Tsuda, T. Nakamura, M. K. Yamamoto, T. Sato, M. Hagio, and Y. Yabugaki, Equatorial Atmosphere Radar (EAR): System description and first results, Radio Sci., 38(3), 1053, doi:10.1029/2002RS002767, 2003.

Garcia, R. R. and S. Solomon, The effects of breaking gravity waves on the dynamics and chemical composition of the mesosphere and lower thermosphere, J. Geophys. Res., 90, 3850-3868, 1985.

Gurevich, A. V., K. Rinnert, and K. Schlegel, The long-wave portion of the plasma turbulence spectrum in the lower E region, Int. Geomagn. Aeron., 1, 15 p., 1997.

Hamilton, K., Comprehensive meteorological modeling of the middle atmosphere: A tutorial review, J. Atmos. Terr. Phys., 58, 1591-1627, 1996.

Hines, C. O., Internal AGWs at ionospheric heights, Can. J. Phys., 38, 1441-1481, 1960.

Holton, J. R., The influence of gravity wave breaking on the general circulation of the middle atmosphere, J. Atmos. Sci., 40, 2497-2507, 1983.

Horinouchi, T., T. Nakamura, and J. Kosaka, Convectively generated mesoscale gravity waves simulated throughout the middle atmosphere, Geophys. Res. Lett., 29(21), doi:10.1029/2002GL016069, 2002.

Houghton, J. T., The stratosphere and the mesosphere, Quart. J. R. Meteor. Soc., 104, 1-29, 1978.

Kawashima, M., Y. Fujiyoshi, M. Ohi, T. Honda, T. Kozu, T. Shimamai, and H. Hashiguchi, Overview of doppler radar observations of precipitating cloud systems in Sumatera island during the first CPEA campaign, J. Meteor. Soc. Jpn., 84A, 33-56, 2006.

Lindzen, R. S., Turbulence and stress owing to gravity wave and tidal breakdown, J. Geophys. Res., 86, 9707-9714, 1981.

Ratnam, M. V., T. Tsuda, Y. Shibagaki, T. Kozu, and S. Mori, Gravity wave characteristics over the equator observed during the CPEA campaign using simultaneous data from multiple stations, J. Meteor. Soc. Jpn., 84A, 239-257, 2006a.

Ratnam, M. V., T. Tsuda, T. Kozu, and S. Mori, Modulation of tropopause structure due to local and global-scale temperature variations: A case study using simultaneous radiosonde and CHAMP/GPS measurements, J. Meteor. Soc. Jpn., 84, 989-1003, 2006b.

Tsuda, T., Y. Murayama, H. Wiryosumarto, S. W. B. Harijono, and S. Kato, Radiosonde observations of equatorial atmospheric dynamics over Indonesia, 2, Characteristics of gravity waves, J. Geophys. Res., 99, 10,507-10,516, 1994.

Tsuda, T., M. Venkat Ratnam, T. Kozu, and S. Mori, Characteristics of 10-day Kelvin wave observed with radiosondes and CHAMP/GPS occultation during the CPEA campaign (April-May, 2004), J. Meteor. Soc. Jpn., 84A, 277-293, 2006.

Vincent, R. A. and M. J. Alexander, Gravity waves in the tropical lower stratosphere: An observational study of seasonal and interannual variability, J. Geophys. Res., 105, 17,971-17,982, 2000.

Warner, C. D. and M. E. McIntyre, On the propagation and dissipation of gravity wave spectra through a realistic middle atmosphere, J. Atmos. Sci., 53, 3213-3235, 1996.

M. Venkat Ratnam, S. P. Alexander, T. Kozu, and T. Tsuda (e-mail: tsuda@rish.kyoto-u.ac.jp) 